\title{
The linguistic integration of Japanese ideophones and its typological implications
}

\author{
KIMI AKITA \\ Nagoya University \\ akita.kimi@nagoya-u.jp
}

\begin{abstract}
This article proposes that two linguistic systems (that is, two languages or registers) with different degrees of morphosyntactic integration of ideophones may apply the same restrictions on ideophones in different ways. In Study 1, the author shows quantitatively that the sentence-type restrictions reported for ideophones in several languages also constrain Japanese ideophones, but to a lesser extent. In Study 2, the author argues that two previously identified restrictions on Japanese ideophonic verbs appear to apply only partially to ideophonic verbs in baby talk and highly playful discourse. It is concluded that the strength of these restrictions is negatively correlated with the overall degree of morphosyntactic integration of ideophones in the language or register.
\end{abstract}

Keywords: ideophone typology, morphosyntactic integration, sentence-type restrictions, verbtype restrictions, Japanese

\section{Résumé}

Cet article propose que deux systèmes linguistiques (c'est-à-dire deux langues ou deux registres d'une langue) dans lesquels les idéophones sont morphosyntactiquement intégrés à des degrés différents peuvent appliquer les mêmes restrictions aux idéophones, mais de façon différente. Dans une première étude, l'auteur montre de manière quantitative que les restrictions sensibles au genre de phrase qui ont été observées dans plusieurs langues contraignent aussi les idéophones japonais, mais dans une moindre mesure. Dans une deuxième étude, on

An earlier version of section 4 was presented at the "Structuring sensory imagery: Ideophones across languages \& cultures" workshop (University of Rochester, 2 May 2014). An earlier version of section 5 was presented at the "Typology of event semantics and argument encoding" workshop at the Thirtieth Conference of the English Linguistic Society of Japan (Keio University, Mita Campus, 11 November 2012). I thank both audiences for their insightful comments. My sincere gratitude also goes to the editors of this special issue as well as the two anonymous $C J L$ reviewers. Any remaining inadequacies are my own. This study was partly supported by three JSPS Grants-in-Aid (no. 24720179, no. 25370425, no. $15 \mathrm{~K} 16741$ ) and by a Spanish Ministry of Science and Innovation grant (no. FFI201345553-C3). 
argumente que deux restrictions précédemment identifiées sur les verbes idéophoniques japonais semblent ne s'appliquer que partiellement aux verbes idéophoniques dans le langage de bébé et le discours ludique. L'auteur conclut que la force de ces restrictions est négativement corrélée avec le degré global d'intégration morphosyntaxique des idéophones dans la langue ou le registre donné.

Mots-clés: Typologie des idéophones, intégration morphosyntaxique, restrictions de sélection (type de phrase), réstrictions de selection (verbe), japonais

\section{INTRODUCTION}

Different languages incorporate ideophonic elements in different ways. ${ }^{1}$ This article argues that ideophones retain some of their prototypical features even when ideophones are well integrated into a linguistic system. The data come from Japanese, which is known as a language with a huge ideophonic inventory (Kakehi et al. 1996, Hamano 1998). Japanese ideophones show a high degree of morphosyntactic integration compared to some other languages, particularly in their colloquial and childish uses. However, close investigations based on quantitative and qualitative methods show that ideophonic features and grammatical constraints are retained in integrated Japanese ideophones.

This article pursues the issue of linguistic integration of ideophones from two case studies in Japanese. One study focuses on sentence-type restrictions on ideophones, which have been reported in some languages but are absent in Japanese, at least in an explicit manner. The other case study takes a further step into the sentence structure, looking at the syntactic and semantic types of verbs that Japanese ideophones are allowed to form in normal and playful/childish discourse. These cases will lead us to the general typological implication that grammatical restrictions that yield clear contrasts in the well-formedness of sentences in one language or one register of a language may be found as preferences in another. ${ }^{2}$ The empirical identification of grammatical phenomena of this type requires a large amount of linguistic data, which are often lacking in ideophone research.

The organization of this article is as follows. In section 2, I outline the major characteristics of Japanese ideophones, with special attention to their morphosyntax.

\footnotetext{
${ }^{1}$ The abbreviations and symbols used in this article are as follows: ACC: accusative; ABC: Aozora Bunko Corpus; AH: Accessibility Hierarchy; BCCWJ: Balanced Corpus of Contemporary Written Japanese; CONJ: conjunctive; COP: copula; DAT: dative; GEN: genitive; IDPH: ideophone; IMP: imperative; NEG: negative; NML: nominalizer; NOM: nominative; NPST: nonpast; PASS: passive; POL: polite; PST: past; QUES: question; QUOT: quotative; SFP: sentencefinal particle; TOP: topic; \#: childish or colloquial.

${ }^{2}$ Similar cases include the typology of relativization. Relativizability is known to conform to the Accessibility Hierarchy $(\mathrm{AH})$ of grammatical relations: subject $>$ direct object $>$ indirect object $>$ oblique $>$ genitive $>$ object of comparison (Keenan and Comrie 1977). Typological investigations based on the $\mathrm{AH}$ primarily concern whether a construction can relativize each $\mathrm{NP}$ position. However, the AH also accounts for the frequency of relativization. The relativization of higher-ranked positions tends to be more frequent (Keenan 1975).
} 
This overview allows me to formulate the hypotheses to be examined in this article. In section 3, corpus data are presented to identify weak sentence-type restrictions on Japanese ideophones. In section 4, corpus- and questionnaire-based approaches are taken to examine the violability of the previously identified syntactic and semantic restrictions on ideophonic verbs in Japanese. In section 5, I conclude by reviewing the present findings from the general perspective of ideophone typology. It is argued that greater linguistic integration of ideophones weakens these grammatical constraints.

\section{Preliminaries}

In this section, I outline the main characteristics of Japanese ideophones, paying special attention to their morphosyntax.

\subsection{Japanese ideophones}

The Japanese lexicon has at least a thousand conventional ideophonic items, more commonly known as "mimetics" in Japanese linguistics (Kakehi et al. 1996, Hamano 1998). They have a set of typical formal and functional features, such as monomoraic (e.g., pon 'popping') and bimoraic roots (e.g., poton 'dropping') (Hamano 1998), reduplicative (e.g., potopoto 'dropping repeatedly') and suffixal morphology (e.g., poton 'dropping') (Tamori and Schourup 1999, Akita 2009: Ch. 5), prosodic prominence (Kita 1997), dynamic semantics (Usuki and Akita 2015), and informality (Tamori and Schourup 1999). Japanese ideophones cover both auditory (e.g., piyopiyo 'tweeting', dosadosa 'thudding') and non-auditory eventualities, with the latter ranging from manner of motion (e.g., sutasuta 'walking briskly') to shine (e.g., kirakira 'twinkling'), texture (e.g., sarasara 'dry and smooth'), pain (e.g., zukizuki 'one's head throbbing'), and psychological experience (e.g., wakuwaku 'excited').

What is of particular relevance to the present article is the morphosyntax of Japanese ideophones. They have maximally five syntactic-categorial possibilities: acategorial, quotative-adverbial, bare-adverbial, verbal, and nominal-adjectival (or simply, nominal) (Kita 1997; Kageyama 2007; Toratani 2013, 2015; Akita and Usuki 2016; Usuki and Akita 2015). Each of these categorial realizations is illustrated in (1).

(1) a. ? Nurunuru, unagi-wa subet-te it-ta. IDPH eel-TOP slip-CONJ go-PST

'Slip-slip, the eel went slipping.'

b. Unagi-wa nurunuru-to subet-te it-ta. eel-TOP IDPH-QUOT slip-CONJ go-PST

'The eel went slipping slipperily.'

c. Unagi-wa nurunuru subet-te it-ta.

(bare-adverbial)

eel-TOP IDPH slip-CONJ go-PST

'The eel went slipping slipperily.'

d. Sono unagi-wa nurunuru-si-ta. (verbal)

that eel-TOP IDPH-do-PST

'The eel felt slippery.' 
e. Sono unagi-wa nurunuru-dat-ta.

(nominal)

that eel-TOP IDPH-COP-PST

'The eel was slippery.'

As illustrated in (1a), acategorial ideophones occur at the left or right edge of a sentence, prosodically separated from the rest of the sentence (Tamori and Schourup 1999: 84-88). This use is quite rare and essentially limited to onomatopoeic ideophones. Unlike the syntactically isolated ideophones prevalent in some languages (Voeltz and Kilian-Hatz 2001), acategorial ideophones in Japanese are only found in highly informal or poetic discourse. Adverbial ideophones are marked with either a quotative particle or zero, as illustrated in (1b) and (1c), respectively. Bare-adverbial ideophones and their host verbs (e.g., nurunuru 'slipping' and sube- 'slip' in (1c)) together behave like loose complex predicates (Toratani 2006, Akita and Usuki 2016). Verbal and nominal uses, illustrated in (1d) and (1e), can also constitute predicative constructions. The verbal construction is primarily headed by the dummy verb su- 'do' (section 4), whereas the nominal construction involves a copula.

The five ideophonic constructions differ from each other in terms of the degree of morphosyntactic integration, as represented as the hierarchy in (2) (Kita 1997, 2001; Akita and Usuki 2016; Dingemanse and Akita 2016). ${ }^{3}$

(2) The morphosyntactic integration of ideophones in Japanese: acategorial $<$ quotative-adverbial $<$ bare-adverbial $<$ verbal $<$ nominal NON-INTEGRATED INTEGRATED

Acategorial ideophones are located at the low end of the hierarchy due to their obvious prosodic independence and their occasional holophrastic realization (i.e., occurrence without non-ideophonic elements). The morphosyntactic integration of other ideophone types is measured by a set of linguistic criteria, such as omissibility and indivisibility (Toratani 2015). Compare the following examples illustrating the two tests with the originals in (1). As (3) shows, acategorial and adverbial ideophones can be omitted without affecting the grammaticality of the sentences where they belong, whereas verbal and nominal ideophones cannot.

(3) Omissibility:

a. Nurunuru, unagi-wa subet-te it-ta.

(acategorial) IDPH eel-TOP slip-CONJ go-PST

'Slip-slip, the eel went slipping.'

b. Unagi-wa nurunuru-to subet-te it-ta.

(quotative-adverbial) eel-TOP IDPH-QUOT slip-CONJ go-PST 'The eel went slipping slipperily.'

c. Unagi-wa nurunuru subet-te it-ta. (bare-adverbial) eel-TOP IDPH slip-CONJ go-PST 'The eel went slipping slipperily.'

${ }^{3}$ This hierarchy simply visualizes the degree of morphosyntactic integration of each ideophonic construction as measured by linguistic tests. It does not involve any implicational relation about the crosslinguistic presence of the five constructions (Akita 2009: Ch. 7). 
d. * Sono unagi-wa nurunuru-si-ta.

(verbal)

that eel-TOP IDPH-do-PST

'The eel felt slippery.'

e. * Sono unagi-wa nurunuru-dat-ta.

that eel-TOP IDPH-COP-PST

'The eel was slippery.'

(nominal)

The sentences in (4) show that the ideophonic parts of verbal and nominal ideophones cannot be separated from their tensed parts (i.e., the verb $s u$ - 'do' and the copula $-d a$ ) by intervening phrases or clauses. Bare-adverbial ideophones exhibit similar but weaker resistance to separation, suggesting that they are combined more tightly with their host predicates than quotative-adverbial ideophones (Akita and Usuki 2016).

(4) Indivisibility:

a. ? Nurunuru, [hure-ru-to] unagi-wa subet-te it-ta. (acategorial) IDPH touch-NPST-when eel-TOP slip-CONJ go-PST

'Slip-slip, when [I] touched [it], the eel went slipping.'

b. Unagi-wa nurunuru-to [hure-ru-to] subet-te it-ta. (quotativeeel-TOP IDPH-QUOT touch-NPST-when slip-CONJ go-PST adverbial)

'The eel went slipping, when [I] touched [it], slipperily.'

c. ?? Unagi-wa nurunuru [hure-ru-to] subet-te it-ta. (bare-adverbial) eel-TOP IDPH touch-NPST-when slip-CONJ go-PST

'The eel went slipping, when [I] touched [it], slipperily.'

d. * Sono unagi-wa nurunuru [hure-ru-to] si-ta. (verbal) that eel-TOP IDPH touch-NPST-when do-PST

'The eel felt, when [I] touched [it], slippery.'

e. * Sono unagi-wa nurunuru [hure-ru-to] dat-ta. (nominal) that eel-TOP IDPH touch-NPST-when COP-PST

'The eel was, when [I] touched [it], slippery.'

Another indivisibility test using focus particles diagnoses verbal ideophones as having looser structural unity than nominal ideophones, as illustrated in (5) (see Kageyama 2007).

(5) a. Sono unagi-wa nurunuru-wa si-ta. that eel-TOP IDPH-TOP do-PST 'The eel indeed felt slippery.'

b. * Sono unagi-wa nurunuru-wa dat-ta. that eel-TOP IDPH-TOP COP-PST 'The eel was indeed slippery.'

(verbal)

(nominal)

\subsection{Hypotheses}

In this article, I hypothesize and explore a negative correlation between the degree of morphosyntactic integration of ideophones and the strength of grammatical restrictions on them. This hypothesis is motivated by the recent empirical investigations into the inverse correlation between the morphosyntactic integration of ideophones 
and their 'expressiveness'. Ideophones are typically accompanied by a set of emphatic features, such as prosodic foregrounding (Nuckolls 1996) and expressive morphology (for instance, vowel lengthening, partial reduplication; Zwicky and Pullum 1987), and the frequency of these 'expressive' features has been found to decrease as a function of the degree of morphosyntactic integration (Dingemanse 2011: Ch. 6; Dingemanse and Akita 2016; Akita, to appear; Dingemanse, to appear; see also Childs 2014). In fact, similar (and more general) discussion has been repeatedly made under somewhat impressionistic notions, such as "ideophonicity/lexicality" (Tamori and Schourup 1999; cf. Newman 2001) and "iconicity" (Akita 2009: Ch. 7). The discussion concludes that ideophones lose their ideophonic tone when they are formally integrated into the sentence structure or become part of the prosaic lexicon. These studies remain somewhat impressionistic because they fail to clearly define the key notions of an ideophonic tone and morphosyntactic integration.

I solve this general problem by focusing on two specific grammatical restrictions on typical ideophones: sentence-type restrictions and verb-type restrictions. These restrictions replace the vague dimension of an ideophonic tone. Moreover, our hierarchy of ideophonic constructions in (2) gives a specific picture to the notion of morphosyntactic integration. Thus, the specific hypotheses to be examined in this article can be stated as in (6).

(6) a. Hypothesis 1 (to be examined crosslinguistically in section 3):

Sentence-type restrictions are weaker (or absent) in ideophones with higher morphosyntactic integration.

b. Hypothesis 2 (to be examined intralinguistically in section 4):

Verb-type restrictions are weaker (or absent) in ideophones with higher morphosyntactic integration.

I examine these hypothesized negative correlations both intra- and cross-linguistically. Both within and across languages, there are differences in how deeply ideophones are morphosyntactically integrated. First, Japanese has five major ideophonic constructions with different degrees of morphosyntactic integration (section 2.1). As I discuss in section 4, language-internal differences in the morphosyntactic integration of ideophones are also found between registers (that is, normal vs. colloquial, childish). Second, the average degree of morphosyntactic integration of Japanese ideophones appears to be higher than that of ideophones in languages like Semai (Austroasiatic; Diffloth 1976) and Kambera (Austronesian; Klamer 1999), which are known to have no ideophonic predicates (Dingemanse, to appear). This idea is further corroborated by the abovementioned stylistic limitations on acategorial ideophones in Japanese. ${ }^{4}$ Based on these facts and assumptions, I examine Hypothesis 1

\footnotetext{
${ }^{4}$ The stylistic limitations on acategorial ideophones are reflected in their low frequency. I found 582 ideophones in the 27 friendly conversations in the Nagoya University Conversation Corpus, a conversation corpus of spoken Japanese (see section 3.2). The frequencies of the five ideophonic constructions were as follows: acategorial, 5.33\%; quotative-adverbial, $37.97 \%$; bare-adverbial, $14.78 \%$; verbal, $31.27 \%$; nominal, $10.65 \%$.
} 
(sentence-type restrictions) in a crosslinguistic context and Hypothesis 2 (verb-type restrictions) within Japanese.

\section{STUDY 1: SENTENCE-TYPE RESTRICTIONS}

In this section, I quantitatively examine Hypothesis 1 by looking at how ideophones are distributed across different types of sentences in a corpus of spoken Japanese, which is assumed to represent high linguistic integration of ideophones (section 2.2).

\subsection{Descriptions}

Sentence-type restrictions have been, sometimes partly and sometimes controversially, noted for ideophones in several languages, including Hausa (Afro-Asiatic, Newman 1968); Kisi (Niger-Congo, Childs 1994); KiVunjo Chaga (Niger-Congo, Moshi 1993); Khmu (Austroasiatic, Svantesson 1983); Chadic, Sundanese, and Korean (isolate, Diffloth 1972); and Chinese (Sino-Tibetan, Aihara and Han 1990, for certain reduplicative items with some ideophonic properties). The sentencetype restrictions restrict the occurrence of ideophones in these languages to basic types of sentences (affirmative-declarative sentences); they cannot occur in nonbasic (interrogative, imperative, and negative) sentences. For example, Newman (1968) observes that, in Hausa, the ideophonic adverbs (termed "descriptive adverbs") illustrated in (7) are subject to the sentence-type restrictions, whereas the quasi-ideophonic adverbs (termed "verbal intensifiers") illustrated in (8) are not. Quasi-ideophonic items appear to have lost some of their ideophonic identity. As I describe in section 3.3, Japanese also has a set of quasi-ideophonic adverbs that are quite free from the sentence-type restrictions.

(7) Hausa ideophonic adverbs:

(Newman 1968: 110-111)

a. Ya fadi sharap.

(affirmative-declarative)

he fall IDPH

'He fell headlong.'

b. * Ya fadi sharap?

'Did he fall headlong?'

(interrogative)

c. * Tashi farat!

(imperative)

get.up IDPH

'Get up in a flash!'

d. * Bai tashi farat ba.

NEG get.up IDPH NEG

(negative)

'He didn't get up in a flash.'

(8) Hausa quasi-ideophonic adverbs:

(Newman 1968: 110-111)

a. Ya kone kurmus.

(affirmative-declarative)

he burn completely

'It burnt to the ground.' 
b. Ya kone kurmus?

(interrogative)

'Did it burn to the ground?'

c. Cika ta pal!

(imperative)

fill it full

'Fill it full!'

d. Bai cika pal ba.

(negative)

NEG fill full NEG

'He didn't fill it up completely.'

On the other hand, Japanese ideophones can readily occur in both basic and non-basic sentences, as illustrated in (9). ${ }^{5}$

(9) a. Ai-wa nikoniko-to warat-ta.

Ai-TOP IDPH-QUOT smile-PST

(affirmative-declarative)

'Ai smiled brightly.'

b. Ai-wa nikoniko-to warat-ta-no?

(interrogative)

Ai-TOP IDPH-QUOT smile-PST-QUES

'Did Ai smile brightly?'

c. Ai, nikoniko-to warai-nasai!

(imperative)

$\mathrm{Ai}$ IDPH-QUOT smile-IMP

'Ai, smile brightly!'

d. Ai-wa nikoniko-to waraw-anakat-ta. (negative)

Ai-TOP IDPH-QUOT smile-NEG-PST

'Ai didn't smile brightly.'

Thus, unlike the languages cited above, Japanese does not have obvious sentence-type restrictions on ideophones. Hypothesis 1 allows us to predict that even ideophones in Japanese, presumably a language with highly integrated ideophones, may exhibit some preference for basic sentences (Prediction 1), and that the preference is greater in constructions with lower morphosyntactic integration, such as the quotative-adverbial construction (Prediction 2). Such a preference will suggest the gradual nature of ideophone typology, in which acceptability contrast in one linguistic system may be retained as frequency contrast in another.

\subsection{Methods}

I used 27 informal conversations between two to four (old) friends in the Nagoya University Conversation Corpus. This subpart of the corpus contains 19 conversations between female speakers, one conversation between male speakers, and seven conversations between male and female speakers. The total length of the conversations was 21.88 hours, and they contained 28,277 sentences (507,208 morphemes). This corpus is appropriate for the present research purpose because,

\footnotetext{
${ }^{5}$ Kita (1997: 389-391) discusses sentence-type restrictions on Japanese ideophones, arguing that only metalinguistic negation is available to sentences with manner-adverbial ideophones. However, he tests this with nominalized clauses, rather than with normal clauses, and many Japanese-speaking linguists, including myself, do not share his judgments.
} 
unlike corpora of monologues and written discourse, it contains many interrogative and imperative sentences.

I obtained 582 tokens of ideophones and 339 tokens of "quasi-ideophones" (Tamori 1980, Tamori and Schourup 1999, among others). I compared ideophones and quasi-ideophones because of their minimal difference. Quasi-ideophones are degree, frequency, or intensity adverbs with putative ideophonic origin, such as dandan 'gradually', dondon 'increasingly', kit-to 'surely', kitin-to 'properly', sot-to 'gently', sukkari 'completely', and zut-to 'all the time'. They are recognizable by their morphological and semantic characteristics. They have prototypical ideophonic shapes, such as reduplicative and suffixal shapes, and, due to their event-general semantics, they are as frequent as non-ideophonic adverbs (Akita 2012, Toratani 2012). In the present corpus, the mean type-token ratios for ideophones and quasiideophones were $43.30 \%$ and $10.11 \%$, respectively. I manually coded the type (that is, affirmative-declarative, interrogative, imperative, or negative) of the sentence containing each ideophone/quasi-ideophone token. Prediction 1 leads us to expect that ideophones should exhibit a greater preference for basic sentences than quasiideophones.

\subsection{Results}

Some instances are cited in (10) and (11). Construction types are coded within the sentences.

(10) Ideophones:

a. Demo gozyuu-en-kurai [Quot-adv babababat-te] oti-tyau-node but 50-yen-about IDPH-QUOT fall-end.up-because [v bikkuri-si]-ta-koto-ga aru-n-desu-kedo-ne. (032, affirmative-declarative) IDPH-do-PST-NML-NOM be-NML-COP.POL-but-SFP 'But as [the payphone] consumed about $¥ 50$ very quickly, [I] was astonished.'

b. Un, wasyoku-da-kedo [ ${ }_{\mathrm{N}}$ kotekote-zya]-naku-tte. (080, negative) yeah Japanese.food-COP-but IDPH-COP.TOP-NEG-and 'Yeah, [I want to have] a Japanese cuisine but not an overly Japanese one.'

(11) Quasi-ideophones:

a. Yoosuruni, “[Bare-adv wazawaza] uke-ru-no?" -tte-i-u in.short IDPH take-NPST-QUES -QUOT-Say-NPST sekai-dat-ta-n-da-kedo... $\quad$ (047) (interrogative) world-COP-PST-NML-COP-but 'In short, it was like "Do you bother to take [the entrance exam]?"

b. Toriaezu, [Quot-adv zut-to] massugu it-tyat-te-kudasai. (004 imperative) for.now IDPH-QUOT straight go-end.up-CONJ-POL.IMP 'For now, please go straight on.'

The data were found to support both of our predictions. First, ideophones appeared more frequently $(92.10 \%)$ than quasi-ideophones $(78.17 \%)$ in basic sentences $\left(\chi^{2}(1)=36.66, p<.001\right)$, supporting Prediction 1 . The detailed distribution of non-basic sentences was not very striking for either ideophones (interrogative, 


\begin{tabular}{lrrrrrrrr}
\hline \hline & \multicolumn{3}{c}{ Ideophones } & & \multicolumn{3}{c}{ Quasi-ideophones } \\
\cline { 2 - 4 } & Basic & Total & \multicolumn{1}{c}{$\%$} & & Basic & Total & $\%$ \\
\hline Acategorial & 31 & 31 & 100.00 & & 1 & 1 & 100.00 \\
Quotative-adverbial & 210 & 221 & 95.02 & & 171 & 221 & 77.38 \\
Bare-adverbial & 79 & 86 & 91.86 & & 65 & 84 & 77.38 \\
Verbal & 166 & 182 & 91.21 & & 9 & 11 & 81.82 \\
Nominal & 50 & 62 & 80.65 & & 19 & 22 & 86.36 \\
Total & 536 & 582 & 92.10 & & 265 & 339 & 78.17 \\
\hline \hline
\end{tabular}

Table 1. Ideophonic/quasi-ideophonic constructions and sentence types

26; imperative, 3 ; negative, 17) or quasi-ideophones (interrogative, 39; imperative, 7 ; negative, 31 ).

Second, the data sorted by construction in Table 1 give partial support to Prediction 2 . The frequency of nominal ideophones in basic sentences is significantly lower than that of the other four categories $\left(\chi^{2}(1)=12.50, p<.001\right)$. This result is not too surprising, since nominal ideophones are at the extreme integrated end of the scale given in (2), repeated here as (12).

(12) The morphosyntactic integration of ideophones in Japanese: acategorial $<$ quotative-adverbial $<$ bare-adverbial $<$ verbal $<$ nominal NON-INTEGRATED INTEGRATED

This property makes them similar to quasi-ideophones (Kita 1997: 391), which occur more freely in non-basic sentences than do ideophones. See (10b) for a nominal ideophone and (11) for quasi-ideophones, in non-basic sentences. In fact, there was no significant difference between the results for nominal ideophones and those for quasi-ideophones $\left(\chi^{2}(4)=1.28, p=.87\right){ }^{6}$

The present results suggest that Japanese ideophones, in particular the less integrated ones, are subject to the sentence-type restrictions, but as a statistical preference. Therefore, aside from the difference between a tendency and a grammatical contrast, both in Japanese and in the languages mentioned in section 3.1, higher morphosyntactic integration is associated with a less restricted distribution. In the next section, I argue that a similar pattern holds for language-internal generalizations about ideophones, focusing on the restrictions on the types of ideophonic verbs in normal and babytalk/playful Japanese.

\section{STUDY 2: VERB-TYPE RESTRICTIONS}

In this section, I discuss the linguistic integration of Japanese ideophones from another angle: their verb-type restrictions in normal and babytalk/playful discourse.

\footnotetext{
${ }^{6}$ The single acategorial use of a quasi-ideophone was excluded from the calculation.
} 
Unlike the crosslinguistic view in section 3, this section takes a close look at how the grammatical restrictions on ideophones differ between two different registers of one language. Specifically, by observing qualitatively and quantitatively how syntactic and semantic restrictions on ideophonic verbs are retained and/or violated in childish/colloquial Japanese, I examine Hypothesis 2: the verb-type restrictions are weaker (or absent) in ideophones with higher morphosyntactic integration.

\subsection{Descriptions}

Japanese ideophonic verbs are highly morphologically integrated, as we saw in section 2 . They are formed with two productive verbalizers. One is $s u$ - 'do', which incorporates non-onomatopoeic ideophones to form various types of complex verbs, as shown by Kageyama's (2007) classification cited in (13a) (see also Akita 2009: Ch. 6, Tsujimura 2014). The other verbalizer is $i w$ - 'say', which combines with any onomatopoeic ideophone to represent the spontaneous emission of sound, as illustrated in (13b) (Toratani 2015, Akita and Usuki 2016). Note that, as shown in (13), the two verbalizers are in complementary distribution. $S u$ - 'do' can never be replaced by $i w$ - 'say', and $i w$ - cannot be replaced by $s u$ - without producing a playful or childish effect, marked with "\#".

(13) a. Ideophonic 'do'-verbs: Activity:

Translational activity:

Psychological:

Physiological:

Physical perception:

Characterizing predication:

b. Ideophonic 'say'-verbs: kyaakyaa-\{iw/??su\}- 'scream' piyopiyo- $\left\{\mathrm{iw} /\right.$ *su $^{\mathrm{s}}$ - 'tweet' banban-\{iw/\#su\}- 'bang' gorogoro- $\{i w / * s u\}$ - 'roar' patapata-\{iw/??su\}- 'flutter' (adapted from Kageyama 2007: 44)

akuseku-\{su/*iw\}- 'work hard'

urouro- $\{s u / * i w\}$ - 'wander around' gakkari-\{su/*iw\}- 'be disappointed' zukizuki-\{su/*iw\}- 'feel (one's head/teeth) throb' guragura- $\{s u / * i w\}$ - 'wobble' assari- $\{$ su/*iw\}- 'taste light'

buиbuu- $\left\{i w /{ }^{*} s u\right\}-$ 'oink, complain' wanwan- $\{i w / * s u\}$ - 'bark' gatyagatya-\{iw/\#su\}- 'clatter' katakata-\{iw/??su\}- 'clatter' zуииzуии- $\{i w / * s u\}$ - 'sizzle'

These morphosyntactically highly integrated uses of ideophones are subject to the following two restrictions (Akita 2009: Ch. 6, Toratani 2015).

(14) a. The anti-transitivity restriction:

Ideophones cannot form highly transitive/causative verbs.

b. The anti-motion restriction:

Ideophones for manner of motion cannot form verbs.

\footnotetext{
${ }^{7}$ As an anonymous reviewer pointed out, the complementary distribution in Japanese ideophonic verbs is particularly interesting when contrasted with the crosslinguistically more common transitive/intransitive alternation using 'do'/'say' verbs (Cohen et al. 2002), such as the ones in Emai (Schaefer and Egbokhare 2002) and Somali (Dhoorre and Tosco 1998). A detailed discussion is beyond the scope of this article.
} 
The existence of the anti-transitivity restriction is already suggested in the lists in (13), which contain only intransitive verbs. In fact, the verbalization of ideophones for highly causative events, such as a causative change of state, results in clear unacceptability (e.g., *paripari-su- 'crack (a pane of glass)', *bokiboki-su- 'crunch (a thick stick)'). These ideophones are instead realized as adverbs (e.g., paripari (-to) war- break with a cracking sound', bokiboki(-to) or- break with a crunching sound'), which are lower in the integration hierarchy in (12).

The anti-motion restriction works more narrowly and is perhaps subsumed by a more general constraint (Akita 2009: Ch. 6). Japanese has a group of ideophones depicting manner of spatial motion, which cannot be verbalized with either $s u$ 'do' or $i w$ - 'say'. If verbalized with $s u$-, these ideophones would have a marginal and highly childish/colloquial tone. As illustrated in (15), this is true for mannerof-motion ideophones for both animate and inanimate entities. They are always realized as adverbs (e.g., nosinosi(-to) aruk- 'walk in a lumbering manner', barabara (-to) kobore- 'drop in a pattering manner').

(15) a. Animate:

nosinosi-\{*\#su/*iw\}- 'lumber' pyokopyoko-\{*\#su/*iw\}- 'hop'

sorosoro-\{*su/*iw\}- 'walk gingerly' sugosugo-\{*su/*iw\}- 'leave dejectedly'

suisui-\{*\#su/*iw\}- 'swim smoothly' sutasuta-\{*\#su/*iw\}- 'walk briskly'

tekuteku-\{*\#su/*iw\}- 'walk lightly' tobotobo-\{*\#su/*iw\}- 'plod'

tokotoko- $\{* \#$ su/*iw $\}$ - 'walk with short steps'

tukatuka-\{*su/*iw\}- 'walk unreservedly'

b. Inanimate or animacy-neutral:

barabara- $\{* \# s u / * i w\}$ - be scattered' daradara- $\{*$ * $u / * i w\}$ - 'drip'

dosadosa- $\left\{{ }^{*} s u / * i w\right\}$ - 'thud'

gorogoro- $\left\{{ }^{*}\right.$ sus $\left./{ }^{*} i w\right\}$ - 'roll (of a heavy object)'

harahara- $\{* \# s u / * i w\}-$ 'flutter (of a leaf)'

horohoro- $\{* \# s u / * i w\}$ - 'run down (of teardrops)'

korokoro- $\{* \# s u / * i w\}-$ 'roll (of a light object)'

poroporo- $\left\{{ }^{*} \#\right.$ su/*iw\}- 'fall (of light, small objects)'

potupotu- $\{* \# s u / * i w\}-$ begin to rain'

suton-to- $\{* \# s u / * i w\}$ - 'fall right on the ground'

Apparent counterexamples can be noted for both restrictions. First, some previous studies of ideophonic verbs include the impact/contact verbs and reflexive verbs listed in (16a) and (16b), respectively. Impact/contact verbs are transitive verbs that do not entail a change of state (Kageyama 2007: 53, Toratani 2013). Reflexive verbs cooccur with body-part NPs (Tsujimura 2005: 148-149, 2014; Kageyama 2007: 47; Toratani 2013: 54-57).

(16) a. Impact/contact verbs:

\#dondon-su- 'pound'

\#gyut-to-su- 'hold tightly'

\#gosigosi-su- 'scrub'

\#kotyokotyo-su- 'tickle'

\#huиhuu-su- 'blow'

\#peropero-su- 'lick'

\#kutyakutya-su- 'chew'

\#tuntun-su- 'poke'

\#tonton-su- 'tap' 
b. Reflexive verbs:

\#(hane-o) batabata-su- 'flap (one's wings)'

\#(asi-o) burabura-su- 'swing (one's legs)'

\#(kuti-o) mogumogu-su- 'move (one's mouth) chewing food'

\#(kuti-o) pakupaku-su- 'open and close (one's mouth) repeatedly'

\#(me-o) patikuri-su- 'blink (one's eyes) in wonderment'

\#(me-o) patipati-su- 'blink (one's eyes)'

Crucially, both types of transitive verbs are low in transitivity (or causativity) and have a clearly childish/playful tone (Kageyama 2007: 48-49). This stylistic property disappears when these ideophones are used adverbially (e.g., dondon(-to) tatak- hit with a bang', burabura(-to) yuras- 'swing repeatedly'). Therefore, all these instances are compatible with the anti-transitivity restriction.

Next, one might regard the ideophonic translational activity verbs listed in (17) (originally termed "manner-of-motion verbs" by Kageyama 2007) as exceptions to the anti-motion restriction. However, as Sugahara and Hamano's (2015) corpusbased investigation suggests, these verbs appear to represent the totality of the activity involving motion, rather than particular rates of motion or movement of particular body parts, and should therefore be included in the "activity" class in (13a).

(17) burabura-su- 'stroll'

tyokomaka-su- 'bustle around'

tyorotyoro-su- 'run around'

urouro-su- 'wander around'

yotiyoti-su- 'toddle'

\author{
?nyoronyoro-su- 'wriggle' \\ tyokotyoko-su- 'run around busily' \\ urotyoro-su- 'run around' \\ yotayota-su- 'totter'
}

In summary, Japanese ideophonic verbs are incompatible with high transitivity and with manner-of-motion meaning. Also important are the clearly childish/ playful tones of some ideophonic 'do'-verbs, notably impact/contact verbs and reflexive verbs. Such examples indicate that the two restrictions do not hold for certain registers of Japanese - namely, babytalk and highly colloquial speech (Akita 2009: Ch. 6; Tsujimura 2009, 2014). Put differently, these special registers appear to integrate ideophones to a greater extent than does the plain register of Japanese. This contrast between registers mirrors the crosslinguistic contrast in the average morphosyntactic integration of ideophones discussed in section 2.2. In what follows, I examine Hypothesis 2: whether the two restrictions on ideophonic verbs in normal Japanese are weaker (or absent) in colloquial/childish Japanese. Study $2 \mathrm{a}$ is a corpus-based study that looks at how the two restrictions on ideophonic verbs are violated in actual informal discourse, and Study $2 b$ is a questionnaire-based study that tests how violable the two restrictions are.

\subsection{Study $2 \mathrm{a}$}

I conducted a corpus-based investigation to see what types of unconventional ideophonic verbs (that is, those violating the anti-transitivity restriction or the antimotion restriction) are used in actual Japanese discourse. I used the Balanced Corpus of Contemporary Written Japanese (BCCWJ), which is a collection containing about 100,000,000 words from not only relatively formal types of discourse (e.g., 
magazines, newspapers, textbooks, and minutes of the $\operatorname{Diet}^{8}$ ) but also highly informal (e.g., online question-and-answer threads and blogs) and creative (e.g., literary works) types of discourse. Using the NINJAL-LWP for BCCWJ system (version 1.00), I searched that corpus for 577 reduplicative ideophones identified by Kakehi et al. (1996).

I obtained 23 types and 46 tokens of unconventional uses of ideophonic 'do'verbs. As the representative instances cited in (18) show, most of the unconventional ideophonic verbs are the "childish/colloquial" types described in section 4.1 (i.e., $(18 \mathrm{a}-\mathrm{c}))$. "Caused-motion" examples may be included in the impact/contact type. For example, kurukuru-su- in (18d) can be understood as representing a twirling action applied to spaghetti.

(18) a. Impact/contact (14 types, 26 tokens):

... karada-o gosigosi-su-ru-toki-ni ...

body-ACC IDPH-do-NPST-when-DAT

'... when [my hamster] scrubs [its] body ...'

(Yahoo! Answers, 2005, BCCWJ)

b. Reflexive (2 types, 11 tokens):

Tada kuti-o pakupaku-su-ru-dake-dat-ta.

just mouth-ACC IDPH-do-NPST-only-COP-PST

'[He] only opened and closed [his] mouth repeatedly.'

(Hiroshi Ito, Abuku Akira-no awa-no tabi [Bubble Akira's bubbly journey], 2005, BCCWJ)

c. Sound emission (1 type, 2 tokens):

Yure-ru-tabi-ni tiisa-na mado-ga gatapisi-si-ta.

shake-NPST-whenever-DAT small-COP window-NOM IDPH-do-PST

'The small window rattled every time [it] shook.'

(Taeko Nakamura, trans., Tubasa-yo, kita-ni [North to the orient], 2002, BCCWJ)

d. Caused-motion (6 types, 7 tokens):

Sonnani kirei-ni kurukuru-si-naku-te i-i-ga ...

so neat-COP IDPH-do-NEG-CONJ good-NPST-but

'Though [you] don't need to twirl [the spaghetti] so neatly ...'

(Yahoo! Answers, 2005, BCCWJ)

Similar results were obtained from two smaller corpora, the Aozora Bunko Corpus (a literary corpus) and the Nagoya University Conversation Corpus (see section 3.2): impact/contact, 2 tokens; reflexive, 2 tokens; sound emission, 4 tokens; caused-motion, 2 tokens. The Aozora Bunko Corpus also contained an instance of a manner-of-motion ideophonic verb, which is cited in (19).

(19) Sosite sore-wa, bon-no naka-de yoriwake-rare-ru

and that-TOP tray-GEN inside-in sort-PASS-NPST

azuki-no-yoo-ni, korokoro-si-ta.

adzuki.bean-GEN-like-COP IDPH-do-PST

'And it [post horse] tumbled like an adzuki bean being sorted on a tray.'

(Yoshiki Hayama, Umi-ni ikuru hitobito [Men who live on the sea], 1926, ABC)

${ }^{8}$ The National Diet is Japan's bicameral legislature. 
The present corpus data suggest that the two restrictions on Japanese ideophonic verbs are not freely violable even in informal and creative registers (see Tsujimura $2009,2013,2014)$. Notably, the three corpora provided no single explicit instance of a causative change-of-state ideophonic verb that would clearly violate the anti-transitivity restriction. Likewise, the high exceptionality of (19) indicates the strength of the antimotion restriction. Moreover, all unconventional sound-emission ideophonic verbs, such as gatapisi-su- 'rattle' in (18c), have natural-sounding 'say'-verb counterparts (e.g., gatapisi-iw- 'rattle') and can safely be considered their ad hoc substitutes.

The limited size of the data set prevents us from making any conclusive argument. In particular, the present data tell us nothing about ideophonic verb forms that were not found. They might or might not be acceptable. Therefore, in the next section, I reinforce the present findings with a questionnaire-based introspective investigation.

\subsection{Study $2 b$}

For a better understanding of the violability of the two restrictions on Japanese ideophonic verbs, I conducted a follow-up study using 80 simple sentences with ideophonic verbs. The stimulus set contained 26 sentences with conventional ideophonic verbs that fall into Kageyama's (2007) classes in (13a), and 24 instances of unconventional ideophonic verbs. Four sentences were constructed for each of the following six semantic types of unconventional ideophonic verbs on the basis of the discussion in section 4.2: impact/contact, reflexive, caused-motion, sound emission, causative change of state, and manner of motion. The remaining 30 sentences were intended to be dummy stimuli that, I assumed, involved unambiguously ungrammatical semantic structures as verbs, such as Mai-ga neko-o nyaanyaa-si-ta Mai meowed the cat' with the intended reading 'Mai made the cat meow.' Two questionnaires with 40 stimuli were created from these sentences.

I asked 43 undergraduate students at Osaka University who are native speakers of Japanese ( 6 female, 37 male) to judge the naturalness of the 40 simple sentences in one of the two questionnaires. Based on the findings in section 4.2, I provided three choices: "natural", "babytalk", and "unnatural". Each questionnaire started with three practice sentences that were assumed to draw three different judgments.

In (20), the most "unnatural" sentence of each of the six types of unconventional ideophonic verbs is cited, along with the percentage of "unnatural" answers for that sentence.

(20) a. Onnanoko-ga huton-o panpan-si-ta.

(impact/contact, $8.70 \%$ )

girl-NOM futon-ACC IDPH-do-PST

'A girl slapped the futon.'

b. Kodomo-ga yubi-o guruguru-si-ta.

(reflexive, 29.17\%)

child-NOM finger-ACC IDPH-do-PST

'The child whirled [his] (index) finger.'

c. Mai-ga tobotobo-si-te i-ta.

Mai-NOM IDPH-do-CONJ be-PST

'Mai was plodding.' 
d. Kodomo-ga to-o garagara-si-ta.

(caused-motion, 54.55\%)

child-NOM door-ACC IDPH-do-PST

'A child rattled the sliding door (shut).'

e. Onnanoko-ga mado-o baribari-si-ta. girl-NOM window-ACC IDPH-do-PST

'A girl shattered the windows.'

f. Kuruma-ga buubuu-si-te i-ta. car-NOM IDPH-do-CONJ be-PST

'A car was zooming.'

The results are shown in Figure 1.

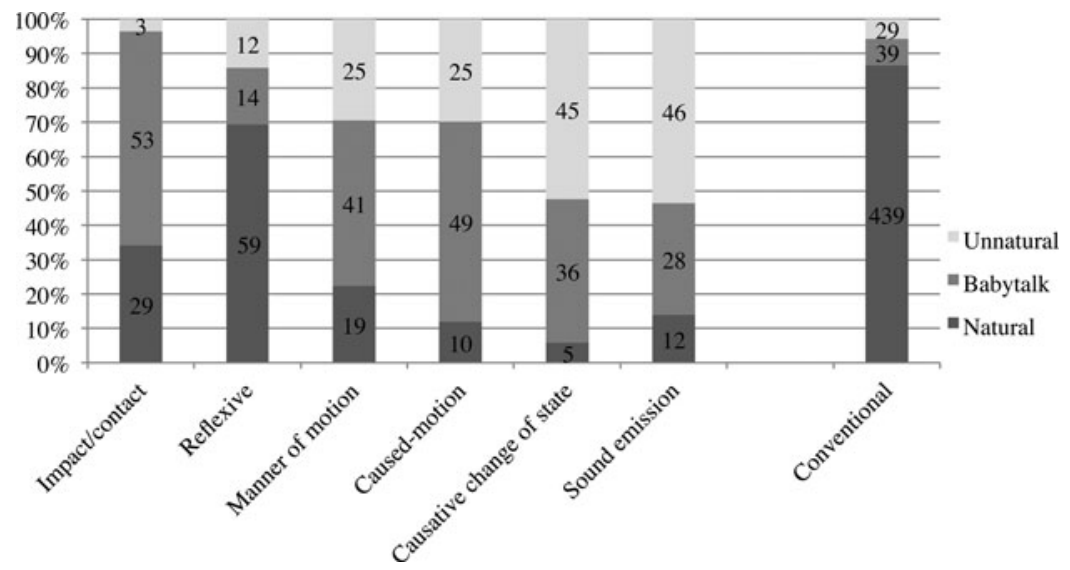

Figure 1. Naturalness of ideophonic verbs

In accordance with the corpus study in section 4.2, both conventional ideophonic verbs (e.g., ukiuki-su- 'feel happy' [psychological]) and impact/contact (e.g., tuntun$s u$ - 'poke') and reflexive ideophonic verbs (e.g., (me-o) kyorokyoro-su- 'move (one's eyes) restlessly'), which mildly violate the anti-transitivity restriction, were found to be highly acceptable. Significantly, many participants judged impact/contact verbs as "babytalk". It was also suggested that babytalk may even allow other unconventional types of ideophonic verbs, particularly manner-of-motion (e.g., pyokopyoko-su'hop') and caused-motion verbs (e.g., kurukuru-su- 'twirl'). However, about half of the participants judged causative change-of-state verbs (e.g., bokiboki-su'crunch (a thick stick)') and onomatopoeic verbs for spontaneous sound emission (e.g., kusukusu-su- 'giggle') as "unnatural", even as child-directed words. Comparing the present perception data with the production data in section 4.2, the consistent dispreference for causative change-of-state ideophonic verbs may reflect the relative precedence of the anti-transitive restriction over the anti-motion restriction. The low acceptability of sound-emission $s u$-verbs appears to be attributed to the participants' awareness of their conventional $i w$-verb counterparts. 
In summary, the present observations of the syntactic/semantic restrictions on ideophonic verbs in Japanese can be rephrased in a similar way to the crosslinguistic discussion of sentence-type restrictions on ideophones in section 3. The two restrictions on ideophonic verbs are weaker, rather than absent, in the babytalk and playful registers of Japanese, which generally integrate ideophones to a greater extent than normal Japanese. What exists as grammatical contrast in one register of a language may be found as preference in another.

\section{CONCLUSION AND TYPOLOGICAL IMPLICATIONS}

In this article, I have discussed the negative correlation between the degree of morphosyntactic integration of ideophones and the strength of grammatical restrictions on them. Study 1 argued that the sentence-type restrictions reported for ideophones in several languages also apply to Japanese ideophones, but as a force that makes ideophones prefer affirmative-declarative sentences. Study 2 found that two semantic/syntactic restrictions on ideophonic verbs in the normal register of Japanese also apply to its babytalk and playful registers, but again to a lesser extent. Assuming that Japanese, particularly its babytalk/playful register, is a language with relatively highly integrated ideophones, the two sets of results support the inverse correlation between morphosyntactic integration and grammatical restrictions. ${ }^{9}$

One inevitable question that remains to be asked is what determines the degree of morphosyntactic integration of ideophones in each linguistic system. The centurylong literature on ideophones does not provide a satisfactory answer to this question. I therefore conclude by listing three possible factors in the morphosyntactic integration or independence of ideophones. The first factor is the so-called "framing typology" (Talmy 2000). Japanese normally encodes a core schema (e.g., Path of motion) in the main verb (e.g., arui-te hair- [walk-Cons enter] 'enter walking'). A co-event (e.g., Manner of motion) expressed by ideophones must therefore be encoded otherwise (e.g., as an adverb, as in sutasuta-to arui-te hair- [IDPH-QUOT walk-Cons enter] 'enter walking briskly'). However, some languages (e.g., Newar, a Sino-Tibetan language) that typically encode a core schema outside the main verb also appear to make frequent use of ideophonic adverbs (Yo Matsumoto, personal communication). Furthermore, languages like French lexicalize both core schemas and ideophony in verbs (Matsumoto 2003). The existence of these exceptions suggests that there are multiple factors in the integration of ideophones. The second possible factor is the colloquial nature of a linguistic system. As we saw with the babytalk and playful registers of Japanese, colloquial language tends to have high flexibility in grammar, and this flexibility may allow ideophones to

\footnotetext{
${ }^{9}$ Related observations have been made in recent phonological and semantic studies of Japanese ideophones. Nasu (2004) identifies some general phonological constraints remaining in the phoneme distribution of innovative ideophones in Japanese cartoons. Inoue (2010) argues that even creative ideophone uses in Japanese literary works follow the general patterns of semantic extension.
} 
come to belong to various categories, including highly integrated ones. The third possibility is the quantitative and/or qualitative abundance of ideophonic inventories. A large ideophonic lexicon with various semantic types may call for grammatical distinctions (see Akita 2009: Ch. 7 for a related discussion). This last possibility (and perhaps the other two possibilities as well) may seem quite naïve, but will still be important in light of their potential connection to the unsettled question about what makes a language rich in ideophones (Childs 1996, Kunene 2001, Nuckolls 2004).

The present study of Japanese ideophones contributes to the ongoing effort to develop a full typology of ideophones. Typological investigations along the lines discussed in this article can benefit from Japanese linguistics, which has both a long history of ideophone research and many well-designed corpora. As I have demonstrated in this article, these historical and technical advantages permit an effective combination of quantitative and qualitative approaches, which is not always easy in fieldwork studies.

\section{REFERENCES}

Aihara, Shigeru, and Xiu-Ying Han. 1990. Gendai-tyuugokugo-ABB-gata-keiyoosi gyakuhairetu-yoorei-ziten [A counter-arranged dictionary of ABB-type adjectives in Modern Chinese]. Tokyo: Kurosio Publishers.

Akita, Kimi. 2009. A grammar of sound-symbolic words in Japanese: Theoretical approaches to iconic and lexical properties of mimetics. Doctoral dissertation, Kobe University.

Akita, Kimi. 2012. Toward a frame-semantic definition of sound-symbolic words: A collocational analysis of Japanese mimetics. Cognitive Linguistics 23(1): 67-90.

Akita, Kimi. To appear. The typology of manner expressions: A preliminary look. In Motion and space across languages and applications, ed. Iraide Ibarretxe-Antuñano, Chapter 1. Amsterdam: John Benjamins.

Akita, Kimi, and Takeshi Usuki. 2016. A constructional account of the "optional" quotative marking on Japanese mimetics. Journal of Linguistics 52(2): 245-275.

Childs, G. Tucker. 1994. African ideophones. In Sound symbolism, ed. Leanne Hinton, Johanna Nichols, and John J. Ohala, 178-204. Cambridge: Cambridge University Press.

Childs, G. Tucker. 1996. Where have all the ideophones gone? The death of a word category in Zulu. Toronto Working Papers in Linguistics 15(2): 81-103.

Childs, G. Tucker. 2014. Constraints on violating constraints: How languages reconcile the twin dicta of "Be different" and "Be recognizably language". Pragmatics and Society 5 (3): Ideophones: Between grammar and poetry, ed. Katherine Lahti, Rusty Barrett, and Anthony K. Webster, 341-354.

Cohen, David, Marie-Claude Simeone-Senelle, and Martine Vanhove. 2002. The grammaticalization of 'say' and 'do': An areal phenomenon in East Africa. In Reported discourse: A meeting ground for different linguistic domains, ed. Tom Güldemann, and Manfred von Rocador, 227-251. Amsterdam: John Benjamins.

Dhoorre, Cabdulqaadir Salaad, and Mauro Tosco. 1998. 111 Somali ideophones. Journal of African Cultural Studies 11(2): 125-156.

Diffloth, Gérard. 1972. Notes on expressive meaning. In Papers from the Eighth Regional Meeting of the Chicago Linguistic Society, ed. Paul M. Peranteau, Judith N. Levi, and Gloria C. Phares, 440-447. Chicago: Chicago Linguistic Society. 
Diffloth, Gérard. 1976. Expressives in Semai. In Austroasiatic Studies, Part I, ed. Philip N. Lenner, Laurence C. Thompson, and Stanley Starosta, 249-264. Honolulu: The University of Hawaii Press.

Dingemanse, Mark. 2011. The meaning and use of ideophones in Siwu. Doctoral dissertation, Max Planck Institute for Psycholinguistics/Radboud University Nijmegen.

Dingemanse, Mark. To appear. Expressiveness and system integration: On the typology of ideophones, with special reference to Siwu. STUF - Language Typology and Universals 70(2): 119-141.

Dingemanse, Mark, and Kimi Akita. 2016. An inverse relation between expressiveness and grammatical integration: On the morphosyntactic typology of ideophones, with special reference to Japanese. Journal of Linguistics (FirstView). doi:10.1017/S002222671600030X.

Hamano, Shoko. 1998. The Sound-Symbolic System of Japanese. Stanford, CA: CSLI Publications.

Inoue, Kazuko. 2010. Onomatope-no retorikku: Giongo/gitaigo-hyoogen-no soohatu-ni kansuru ninti-gengogaku-teki-kenkyuu [Rhetoric of onomatopoeia: Cognitive linguistic study on neologism of onomatopoeia and mimetics]. Doctoral dissertation, Osaka University.

Kageyama, Taro. 2007. Explorations in the conceptual semantics of mimetic verbs. In Current issues in the history and structure of Japanese, ed. Bjarke Frellesvig, Masayoshi Shibatani, and John Smith, 27-82. Tokyo: Kurosio Publishers.

Kakehi, Hisao, Ikuhiro Tamori, and Lawrence Schourup. 1996. Dictionary of iconic expressions in Japanese. Berlin/New York: Mouton de Gruyter.

Keenan, Edward L. 1975. Variation in universal grammar. In Analyzing variation in language, ed. Ralph W. Fasold, and Roger W. Shuy, 136-148. Washington, DC: Georgetown University Press.

Keenan, Edward L., and Bernard Comrie. 1977. Noun phrase accessibility and universal grammar. Linguistic Inquiry 8(1): 63-99.

Kita, Sotaro. 1997. Two-dimensional semantic analysis of Japanese mimetics. Linguistics 35 (2): 379-415.

Kita, Sotaro. 2001. Semantic schism and interpretive integration in Japanese sentences with a mimetic: A reply to Tsujimura. Linguistics 39(2): 419-436.

Klamer, Marian. 1999. Austronesian expressives and the lexicon. In Proceedings of AFLA 6: Working papers in linguistics, ed. Catherine Kitto and Carolyn Smallwood, 201-219. Toronto: University of Toronto.

Kunene, Daniel P. 2001. Speaking the act: The ideophone as a linguistic rebel. In Ideophones, ed. Friedrich K. Erhard Voeltz, and Christa Kilian-Hatz, 183-192. Amsterdam: John Benjamins.

Matsumoto, Yo. 2003. Typologies of lexicalization patterns and event integration: Clarifications and reformulations. In Empirical and theoretical investigations into language: A festschrift for Masaru Kajita, ed. Shuji Chiba et al., 403-417. Tokyo: Kaitakusha. (Republished: Cognitive linguistics, ed. Adele E. Goldberg, 422-439, London: Routledge. [2011])

Moshi, Lioba. 1993. Ideophones in KiVunjo-Chaga. Journal of Linguistic Anthropology 3(2): 185-216.

Nasu, Akio. 2004. Sinzoo-onomatope-no on'in-koozoo-to bunsetu-no muhyoosei [Phonological structure of mimetic neologisms and segmental unmarkedness]. Japanese Linguistics 16: 69-91.

Newman, Paul. 1968. Ideophones from a syntactic point of view. Journal of West African Languages 5: 107-117. 
Newman, Paul. 2001. Are ideophones really as weird and extra-systematic as linguists make them out to be? In Ideophones, ed. Friedrich K. Erhard Voeltz, and Christa KilianHatz, 251-258. Amsterdam: John Benjamins.

Nuckolls, Janis B. 1996. Sounds like life: Sound-symbolic grammar, performance, and cognition in Pastaza Quechua. Oxford: Oxford University Press.

Nuckolls, Janis B. 2004. To be or not to be ideophonically impoverished. Texas Linguistic Forum 47: Proceedings of the Eleventh Annual Symposium about Language and Society: 131-142.

Schaefer, Ronald P., and Francis O. Egbokhare. 2002. On the status of Do/sAY verbs with Emai ideophones. Anthropological Linguistics 44(3): 278-295.

Sugahara, Takashi, and Shoko Hamano. 2015. A corpus-based semantic analysis of Japanese mimetic verbs. In Iconicity: East meets West, ed. Masako K. Hiraga, William J. Herlofsky, Kazuko Shinohara, and Kimi Akita, 143-160. Amsterdam: John Benjamins.

Svantesson, Jan-Olof. 1983. Катти phonology and morphology. Lund: Gleerups.

Talmy, Leonard. 2000. Toward a cognitive semantics, Vol. II: Typology and process in concept structuring. Cambridge, MA: The MIT Press.

Tamori, Ikuhiro. 1980. Cooccurrence restrictions on onomatopoeic adverbs and particles. Papers in Japanese Linguistics 7: 151-171.

Tamori, Ikuhiro, and Lawrence Schourup. 1999. Onomatope: Keitai-to imi [Onomatopoeia: Form and meaning]. Tokyo: Kurosio Publishers.

Toratani, Kiyoko. 2006. On the optionality of to-marking on reduplicated mimetics in Japanese. In Japanese/Korean linguistics 14, ed. Timothy J. Vance, and Kimberly Jones, 415-422. Stanford, CA: CSLI Publications.

Toratani, Kiyoko. 2012. The role of sound-symbolic forms in Motion event descriptions: The case of Japanese. Review of Cognitive Linguistics 10(1): 90-132.

Toratani, Kiyoko. 2013. Constructions in RRG: A case study of mimetic verbs in Japanese. In Linking constructions into functional linguistics: The role of constructions in grammar, ed. Brian Nolan, and Elke Diedrichsen, 41-66. Amsterdam: John Benjamins.

Toratani, Kiyoko. 2015. Iconicity in the syntax and lexical semantics of sound-symbolic words in Japanese. In Iconicity: East meets West, ed. Masako K. Hiraga, William J. Herlofsky, Kazuko Shinohara, and Kimi Akita, 125-141. Amsterdam: John Benjamins.

Tsujimura, Natsuko. 2005. A constructional approach to mimetic verbs. In Grammatical constructions: Back to the roots, ed. Mirjam Fried, and Hans C. Boas, 137-154. Amsterdam: John Benjamins.

Tsujimura, Natsuko. 2009. Onomatope-doosi-no imi/koo-koozoo-no iti-koosatu [Examination of the meaning and argument structure of mimetic verbs]. KLS 29: Proceedings of the Thirty-Third Annual Meeting of the Kansai Linguistic Society, 334-343.

Tsujimura, Natsuko. 2013. What does mimetic meaning really mean? Paper presented at the Workshop on Grammar of Mimetics, SOAS, University of London, London.

Tsujimura, Natsuko. 2014. Mimetic verbs and meaning. In Morphology and meaning, ed. Franz Rainer, Francesco Gardani, Hans Christian Luschützky, and Wolfgang U. Dressler, 303-314. Amsterdam: John Benjamins.

Usuki, Takeshi, and Kimi Akita. 2015. What's in a mimetic?: On the dynamicity of its iconic stem. In Iconicity: East meets West, ed. Masako K. Hiraga, William J. Herlofsky, Kazuko Shinohara, and Kimi Akita, 109-123. Amsterdam: John Benjamins.

Voeltz, Friedrich K. Erhard, and Christa Kilian-Hatz, ed. 2001. Ideophones. Amsterdam: John Benjamins.

Zwicky, Arnold M., and Geoffrey K. Pullum. 1987. Plain morphology and expressive morphology. In Proceedings of the Thirteenth Annual Meeting of the Berkeley Linguistics Society, 330-339. 


\section{CORPORA}

Aozora Bunko. <http://www.aozora.gr.jp> 6 March 2012.

Balanced Corpus of Contemporary Written Japanese (BCCWJ).

Nagoya University Conversation Corpus. <https://dbms.ninjal.ac.jp/nuc/> 19 March 2014.

NINJAL-LWP for BCCWJ. <http://nlb.ninjal.ac.jp> 3 September 2012. 